\title{
Prediction of the risk of C5 palsy after posterior laminectomy and fusion with cervical myelopathy using a support vector machine: an analysis of 184 consecutive patients
}

Haosheng Wang ${ }^{1 \dagger}$, Zhi-Ri Tang ${ }^{2 \dagger}$, Wenle $\mathrm{Li}^{3,4+}$, Tingting Fan ${ }^{5}$, Jianwu Zhao ${ }^{1}$, Mingyang Kang ${ }^{1}$, Rongpeng Dong ${ }^{1}$ and Yang Qu ${ }^{1 *}$

\begin{abstract}
Background: This study aimed to predict C5 palsy (C5P) after posterior laminectomy and fusion (PLF) with cervical myelopathy (CM) from routinely available variables using a support vector machine (SVM) method.

Methods: We conducted a retrospective investigation based on 184 consecutive patients with CM after PLF, and data were collected from March 2013 to December 2019. Clinical and imaging variables were obtained and imported into univariable and multivariable logistic regression analyses to identify risk factors for C5P. According to published reports and clinical experience, a series of variables was selected to develop an SVM machine learning model to predict C5P. The accuracy (ACC), area under the receiver operating characteristic curve (AUC), and confusion matrices were used to evaluate the performance of the prediction model.
\end{abstract}

Results: Among the 184 consecutive patients, C5P occurred in 26 patients (14.13\%). Multivariate analyses demonstrated the following 4 independent factors associated with C5P: abnormal electromyogram (odds ratio [OR] $=7.861)$, JOA recovery rate $(O R=1.412)$, modified Pavlov ratio $(O R=0.009)$, and presence of $C 4-C 5$ foraminal stenosis ( $O R=15.492)$. The SVM model achieved an area under the receiver operating characteristic curve (AUC) of 0.923 and an ACC of 0.918. Additionally, the confusion matrix showed the classification results of the discriminant analysis.

Conclusions: The designed SVM model presented satisfactory performance in predicting C5P from routinely available variables. However, future external validation is needed.

Keywords: C5 palsy, Cervical myelopathy, Posterior laminectomy and fusion, Risk factors, Outcomes, Support vector machine

\footnotetext{
* Correspondence: quy@jlu.edu.cn

${ }^{\dagger}$ Haosheng Wang, Zhi-Ri Tang, and Wenle Li contributed to the work equally and should be regarded as co-first authors.

'Department of Orthopedics, Second Hospital of Jilin University, 218 Ziqiang

Street, Changchun, Jilin, People's Republic of China

Full list of author information is available at the end of the article
}

C C The Author(s). 2021 Open Access This article is licensed under a Creative Commons Attribution 4.0 International License, which permits use, sharing, adaptation, distribution and reproduction in any medium or format, as long as you give appropriate credit to the original author(s) and the source, provide a link to the Creative Commons licence, and indicate if changes were made. The images or other third party material in this article are included in the article's Creative Commons licence, unless indicated otherwise in a credit line to the material. If material is not included in the article's Creative Commons licence and your intended use is not permitted by statutory regulation or exceeds the permitted use, you will need to obtain permission directly from the copyright holder. To view a copy of this licence, visit http://creativecommons.org/licenses/by/4.0/ The Creative Commons Public Domain Dedication waiver (http://creativecommons.org/publicdomain/zero/1.0/) applies to the data made available in this article, unless otherwise stated in a credit line to the data. 


\section{Background}

Postoperative C5 palsy (C5P) is a well-known and frequent complication of cervical surgery [1]. The main clinical manifestations of C5P include sensation disorder, persistent pain, muscle weakness, and motor motion weakness in the innervation area of C5 [2-4]. Despite its low incidence and relatively long-term outcomes, C5P greatly influences the quantity of life, work productivity, and patient-doctor trust during the recovery period [5, 6]. As noted in previous studies, the incidence of C5P is higher in patients after posterior laminectomy and fusion (PLF) than in those who are treated with posterior laminoplasty (PLP) among posterior cervical surgeries [7]. Nevertheless, there is still controversy regarding the high incidence of C5P in patients with PLF [8, 9]. Because the incidence of $\mathrm{C5P}$ is an essential indicator of the efficiency of cervical surgery, identification of the risk factors related to $\mathrm{C} 5 \mathrm{P}$ and prediction of the risk of C5P following PLF are of major interest.

In general, posterior spinal decompression is the primary treatment for multi-segmental cervical myelopathy compared with anterior procedures [10]. PLP and PLF are the main procedures of spinal decompression that can be performed posteriorly [10]. In contrast to PLP, PLF can provide wider decompression and avoid kyphotic changes and axial neck pain. However, there is a higher incidence of C5P in PLF, which is the major disadvantage in PLF $[7,11]$. In previous studies, excessive posterior traction or tethering of the C5 root was recognized as a vital cause. To date, most studies have mainly focused on the incidence and imaging parameters. Unfortunately, the mechanism of C5P remains controversial, and there is a lack of a reliable prediction tool so far. In recent years, machine learning technology has received growing attention in medicine and healthcare [12-14]. The support vector machine (SVM), proposed by VAPNIK in 1997, is a linear and nonlinear classification method. Its basic idea is to map the data to be classified into a higher dimensional feature space with certain fault-tolerant conditions using appropriate kernel functions [15]. The classification hyperplane categorizes the data. The supporting variable is the nearest sample point when determining the best classification hyperplane. SVM has been widely used in the field of biomedicine and has demonstrated good performance [16, 17].

In this work, we aimed to predict the risk of C5 palsy after PLF with cervical myelopathy (CM) by routing available parameters using the SVM method.

\section{Methods}

\section{Patients and clinical features}

The researchers were granted ethics approval by the ethics committee of the Second Hospital of Jilin University
(Project ID: 20151213002N). In this work, 214 consecutive patients who underwent PLF for nontraumatic CM between March 2013 and December 2019 were enrolled. A total of 214 patients were included from the medical record system and radiological information system. Based on our search strategy, cervical myelopathy was set as the keyword for the search, and patients with kyphotic alignment of the cervical spine, segmental instability, and preoperative axial neck pain $>5$ on the pain visual analog scale (VAS, 0-10) were eligible for the research. All cases were operated on by the same orthopedic surgeon. We performed PLF using cervical lateral mass screw and/or cervical pedicle screw placement with localized local bone grafts obtained from laminectomy. Foraminotomies at the symptomatic levels were performed, preserving more than $50 \%$ of the facet joints. Patients were divided into 2 groups depending on the presence or absence of C5P (C5P and No C5P group). C5P was defined as the new onset of sensory disturbance and pain in the deltoid (< grade 3 or > grade 1 decrease from baseline) and C5 dermatome area 6 weeks after surgery. Ultimately, a total of 184 patients were enrolled in this study. All patients had a minimum follow-up of at least 1 year. To validate the model, 10-fold crossvalidation was adopted. After admission, patients' age, sex, body mass index (BMI), history of hypertension, history of diabetes mellitus, and smoking were recorded. Parameters of physical examination and preoperative electromyography were included. Additionally, the preoperative, postoperative, and Japanese Orthopaedic Association (JOA) recovery rates were collected. Finally, the number of levels decompressed and the number of fusion levels were documented.

\section{Image acquisition and radiographic evaluation}

All patients underwent cervical radiography (X-ray), computer tomography $(\mathrm{CT})$, and magnetic resonance imaging (MRI) detection at the Medical Imaging Center, Second Hospital of Jilin University before they received surgical treatment. The cervical curvature index (CCI) was measured as follows. The line between $\mathrm{C} 2$ and the posteroinferior margin of the $\mathrm{C} 7$ cervical vertebral body was made as line $L$. The vertical lines from the posteroinferior margin of each vertebral body from C3 to C6 to line A were $x_{1}, x_{2}, x_{3}$, and $x_{4}$, respectively. If the posteroinferior margin of C3 to C6 was located on the dorsal cervical side of line $L$, the value of a was recorded as a negative value. The CCI was the percentage of the sum of $x_{1}$ to $x_{4}$ and the value of $L\left[C C I=\left(x_{1}+x_{2}+x_{3}+x_{4}\right) /\right.$ $L \times 100 \%$ ] (Fig. 1a) [18]. The preoperative and postoperative CCIs were calculated in this study. Next, the C2-7 sagittal vertical axis (C2-7 SVA) was measured preoperatively and postoperatively using the following method. The distance between the center point through $\mathrm{C} 2$ and 

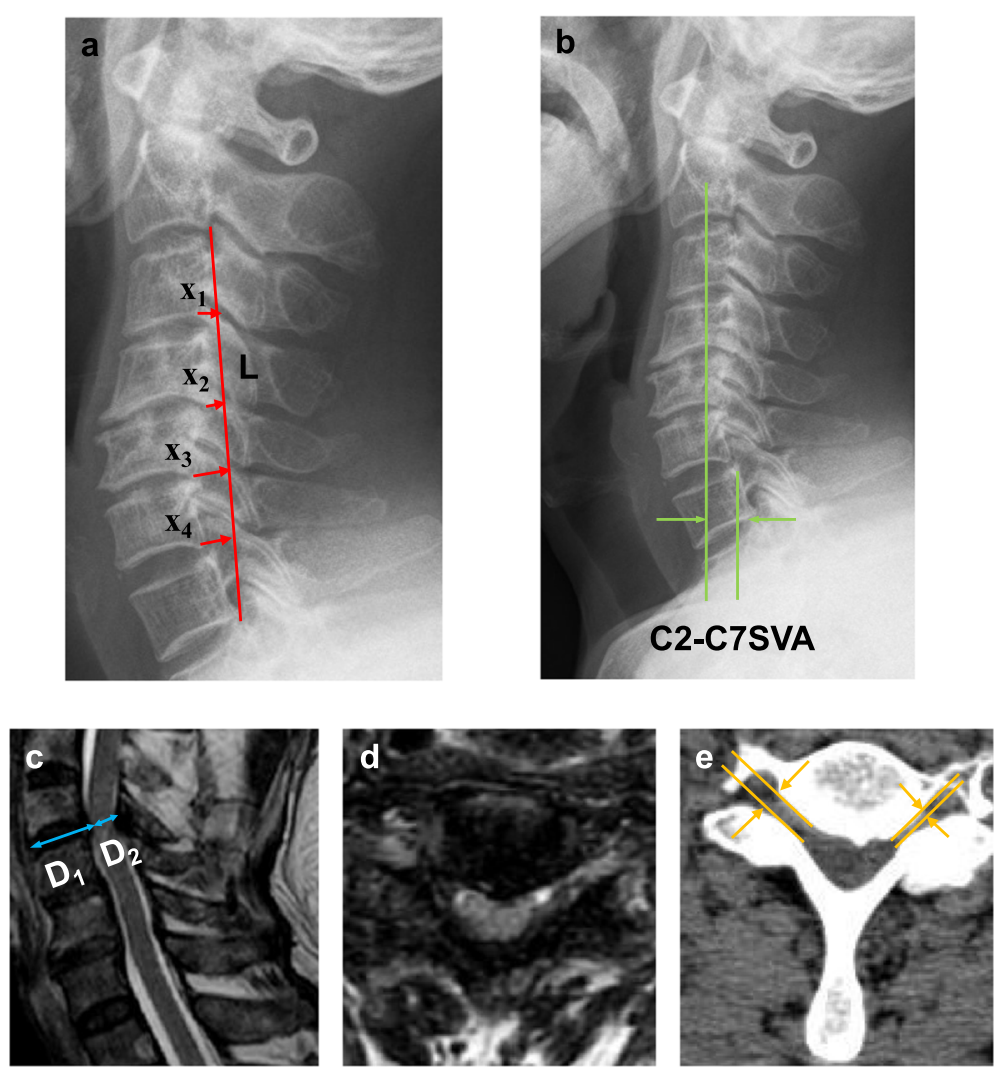

Fig. 1 Radiographic evaluation. a CCI on cervical spine X-rays. CCl: Line $\mathrm{x}$ is the distance between the posterior inferior points of C2 and C7. The distances between the posterior inferior points of $\mathrm{C} 3-\mathrm{C} 6$ and line $\mathrm{L}$ are called a1 to a4, respectively. The CCl is computed by the following formula: $\mathrm{CCl}=\left(x_{1}+x_{2}+x_{3}+x_{4}\right) / L \times 100 \%$. When posterior inferior points of C3-C6 are behind line $L$, the values of $x_{1}$ to $x_{4}$ are negative. $\mathbf{b} C 2-7$ SVA on cervical spine $X$-rays. The distance between the center point through C2 and the vertical line of the posterosuperior corner of C7 was defined as C2-C7 SVA. c Modified Pavlov ratio on sagittal T2-weighted MRI. Pavlov ratio ( $=D_{1} / D_{2}$, vertebral body spinal canal ratio). $\mathbf{d}$ Presence of protruding lesions at the anterior portion of the spinal cord. e Foraminal stenosis between $C 4$ and $C 5$ on axial $C T$ image. The yellow arrows indicate foraminal dimension

the vertical line of the posterosuperior corner of $\mathrm{C} 7$ was defined as C2-C7 SVA (Fig. 1b) [19]. Severe spinal cord compression was measured by the modified Pavlov ratio on sagittal T2-weighted MRI (Fig. 1c and d) [20]. C4-C5 foramen stenosis was defined as $50 \%$ of normal or $50 \%$ of the mean value of the upper and lower cervical foramina in the case of foramen stenosis on CT axial images (Fig. 1e).

\section{Support vector machine}

Recently, SVM has been used to solve various biomedical problems. SVM is a supervised machine learning method based on structural risk minimization principles to minimize training and general error rates and establish a plane so that positive and negative samples can be distinguished in multidimensional space. SVM maps features into a high-dimensional feature space by a kernel function. The radial basis function (RBF) kernel function was adopted in this work [21]. The input feature format can be recorded as "txt" or "xlsx" and uploaded to the support vector machine. The SVM in this paper adopts a linear kernel with a parameter $\mathrm{C}$ of 1.0. In this study, 10 -fold cross-validation was adapted to evaluate the performance of the SVM model. (The ratio of the training and test sets was 9:1. After all the data are applied for the test once, the evaluation process is over, which shows the SVM model's general capability.) Open source, efficient, and free programming languages Python 3.7 and Scikit-learn 0.21.2 packages were used to build machine learning platforms [22]. The performance of SVM was evaluated by the area under the receiver operating characteristic curve (AUC), accuracy (ACC), and confusion matrices. The ACC was determined by the following formula: $\mathrm{ACC}=(\mathrm{TP}+\mathrm{TN}) /(\mathrm{TP}+\mathrm{TN}+\mathrm{FP}+\mathrm{FN})$. In this equation, $\mathrm{TP}$ : true positive; $\mathrm{TN}$ : true negative; $\mathrm{FP}$ : false positive; and FN: false negative. The code used to implement the support vector machine algorithm is shown in the supplementary material. 


\section{Statistical analysis}

Statistical analysis was performed using SPSS (IBM SPSS 26.0, SPSS Inc). Continuous variables are presented as the means (SD), and categorical variables are presented as frequencies (percentages). If the distributions of continuous variables were normal, Student's $t$ tests were applied. Conversely, if normality tests failed, MannWhitney tests were used. For categorical variables, $x^{2}$ tests or Fisher exact tests were used to compare two groups. To better understand the relationship between the clinical and imaging parameters and C5P, logistic regression was used to explore the independent risk factors for C5P. In this study, univariate analysis was performed to identify the potential risk factors. Then, variables with a value of $p<0.2$ in the univariate analysis were included in a multivariate logistic regression model. Given the number of events available, inclusion variables were set to ensure the parsimony of the final logistic regression model [23]. Note that feature selection was utilized to select a subset of related features for application in the machine that learned the model for shortening training time, preventing dimensionality's curse, and making models simpler. Of note, the features selected for machine learning models do not necessarily need to be exactly the same as independent risk factors in multivariate regression analysis $[24,25]$.

\section{Results}

Among the 184 consecutive patients, C5P occurred in $26(14.13 \%)$ and did not occur in 158. The mean age was $63.0 \pm 11.4$ years, and 76 patients $(53.3 \%)$ were male. There were no statistically significant differences in age, history of hypertension, history of smoking, or history of diabetes mellitus between the C5P and No C5P groups. Compared to the No C5P group, the BMI was higher in the C5P group $(p<0.01)$. We found a significantly higher proportion of abnormal electromyogram (EMG) results in the C5P group (20/76.9\%) than in the No C5P group $(58 / 36.7 \%)(p<0.001)$. The pathological reflexes and postoperative JOA score did not show significant differences between the two groups. Notably, the preoperative JOA score (median 12.9 [IQR 11.4, 14.8]) in the C5P group was significantly higher than that in the No C5P group (median 10.4 [IQR 8.1, 12.5]). The JOA recovery rate (median 61.3 [IQR 55.6, 68.6]) in the C5P group was significantly higher than that in the No C5P group (median 77.4 [IQR 72.4, 81.3]). The CCI change and preoperative and postoperative C2-7 SVA did not differ significantly between the C5P and No C5P groups. The modified Pavlov ratio was lower in the C5P group [mean, SD. $0.31(0.11)$ ] than in No C5P group [mean, SD. 0.34 (0.14)]. The proportion of C4-C5 foraminal stenosis was significantly higher in the C5P group (129/ $81.6 \%)$ than in the No C5P group $(4 / 15.4 \%)(p<0.001)$.
The number of levels decompressed in the C5P group [mean, SD. $3.2(0.9)]$ was lower compared with that in the No C5P group [mean, SD. 3.8 (1.2)]. The number of fusion levels was significantly different between the C5P group [mean, SD. $3.9(0.5)$ ] and No C5P group [mean, SD. $4.2(0.6)]$. The detailed results of the parameters are shown in Table 1. Univariate and multivariate logistic regression analyses (Table 2) revealed that abnormal electromyograms, the JOA recovery rate, the modified Pavlov ratio, and the presence of foraminal stenosis C4C5 were independently associated with C5P.

Seven features were selected as the input of the SVM model, including abnormal electromyogram, preoperative CCI, JOA recovery rate, preoperative C2-7 SVA, modified Pavlov ratio, presence of foraminal stenosis C4-C5, and number of levels decompressed. Based on the prediction results of 184 patients, the ROC curve of the prediction model is shown in Fig. 2a, and the AUC was 0.923. Additionally, the ACC of the prediction model was 0.918 . The confusion matrix shows the classification results of the discriminant analysis (Fig. 2b).

\section{Discussion}

In this study, the relationship between clinical parameters and C5P was evaluated, and the independent risk factors were identified by multivariate logistic regression involving 184 consecutive patients with CM after LF. An SVM model was established and applied to predict C5P. A range of evaluation indexes showed that our model had good performance and promising clinical applications.

In patients with $\mathrm{C} 5$ nerve root palsy, approximately $50 \%$ may experience hyperalgesia with or without pain and muscle weakness in the $\mathrm{C} 5$ innervation area, whereas the rest only experience motor weakness. C5 nerve root palsy is usually unilateral, although $5 \%$ to $7 \%$ of patients may present with bilateral symptoms [2628]. It can occur from immediately after surgery to 2 months after surgery, and most cases occur 1 month after surgery. Some scholars emphasize that C5 nerve root palsy occurs $24 \mathrm{~h}$ after surgery to distinguish intraoperative nerve injury $[4,10,29]$. C5 nerve root palsy has a good prognosis, with approximately $70 \%$ of patients recovering within 3 to 6 months and the vast majority of patients $(96 \%)$ recovering within 2 years, but $20 \%$ still have residual partial pain symptoms $[11,29]$.

Notably, C5P occurred in 26 (14.13\%) of 184 patients who underwent posterior cervical LF for the treatment of $\mathrm{CM}$, which is in line with a previous study. In this study, the onset of C5P varied from 1 to 8 days postoperatively, with a mean of 3.9 days. Nevertheless, there was no immediate postoperative neurological deficit. Thus, it is prudent to speculate that the occurrence of C5P may not be due to a direct injury caused by surgery 
Table 1 Comparison of variables between the C5P group and No-C5P group

\begin{tabular}{|c|c|c|c|c|}
\hline & Total & No C5P & C5P & $P$ \\
\hline Number of patients & 184 & 158 & 26 & \\
\hline Age (years, \%) & & & & 0.51 \\
\hline$<40$ & $3(1.6)$ & $2(1.3)$ & $1(3.8)$ & \\
\hline $40-50$ & $20(10.9)$ & $16(10.1)$ & $4(15.4)$ & \\
\hline $50-60$ & $45(24.5)$ & $40(25.3)$ & $5(19.2)$ & \\
\hline $60-70$ & $61(33.2)$ & $54(34.2)$ & $7(26.9)$ & \\
\hline$\geq 70$ & $55(29.9)$ & $46(29.1)$ & $9(34.6)$ & \\
\hline $\operatorname{Sex}(\%)$ & & & & 0.402 \\
\hline Female & $86(46.7)$ & $76(48.1)$ & $10(38.5)$ & \\
\hline Male & $98(53.3)$ & $82(51.9)$ & $16(61.5)$ & \\
\hline History of hypertension (\%) & & & & 1 \\
\hline No & $146(79.3)$ & $125(79.1)$ & $21(80.8)$ & \\
\hline Yes & $38(20.7)$ & $33(20.9)$ & $5(19.2)$ & \\
\hline DM (\%) & & & & 0.229 \\
\hline No & $138(75.0)$ & $121(76.6)$ & $17(65.4)$ & \\
\hline Yes & $46(25.0)$ & $37(23.4)$ & $9(34.6)$ & \\
\hline History of smoking (\%) & & & & 0.345 \\
\hline No & $160(87.0)$ & $139(88.0)$ & $21(80.8)$ & \\
\hline Yes & $24(13.0)$ & $19(12.0)$ & $5(19.2)$ & \\
\hline $\mathrm{BMI}\left(\mathrm{kg} / \mathrm{m}^{2}, \%\right)$ & & & & 0.003 \\
\hline$\leq 18.4$ & $3(1.6)$ & $0(0.0)$ & $3(11.5)$ & \\
\hline $18.5-23.9$ & $29(15.8)$ & $23(14.6)$ & $6(23.1)$ & \\
\hline $24.0-27.9$ & $42(22.8)$ & $37(23.4)$ & $5(19.2)$ & \\
\hline$\geq 28.0$ & $110(59.8)$ & $98(62.0)$ & $12(46.2)$ & \\
\hline Electromyogram abnormal (\%) & & & & $<0.001$ \\
\hline No & $106(57.6)$ & $100(63.3)$ & $6(23.1)$ & \\
\hline Yes & $78(42.4)$ & $58(36.7)$ & $20(76.9)$ & \\
\hline Pathological reflexes (\%) & & & & 0.242 \\
\hline Strong positive & $52(28.3)$ & $48(30.4)$ & $4(15.4)$ & \\
\hline Positive & $89(48.4)$ & $76(48.1)$ & $13(50.0)$ & \\
\hline Weak positive & $34(18.5)$ & $27(17.1)$ & $7(26.9)$ & \\
\hline Negative & $9(4.9)$ & $7(4.4)$ & $2(7.7)$ & \\
\hline Preoperative JOA score & $10.7[8.5,12.7]$ & $10.4[8.1,12.5]$ & $12.9[11.4,14.8]$ & $<0.001$ \\
\hline Postoperative JOA score & $13.1[11.7,14.7]$ & $13.0[11.7,14.3]$ & $14.6[9.1,17.3]$ & 0.184 \\
\hline JOA recovery rate & $75.5[70.1,80.6]$ & $77.4[72.4,81.3]$ & $61.3[55.6,68.6]$ & $<0.001$ \\
\hline Preoperative CCl & $6.3[5.0,7.6]$ & $6.1[4.9,7.4]$ & $7.4[6.6,8.3]$ & 0.004 \\
\hline Postoperative CCl & $10.5[8.5,12.3]$ & $10.4[8.3,12.1]$ & $11.3[9.6,14.1]$ & 0.062 \\
\hline CCl Change & $4.9[3.8,6.3]$ & $4.7[3.8,6.1]$ & $5.8[3.7,7.0]$ & 0.134 \\
\hline Preoperative C2-7 SVA (mm) & $23.4[17.0,27.4]$ & $22.2[16.9,27.0]$ & $23.8[19.7,29.0]$ & 0.35 \\
\hline Postoperative C2-7 SVA (mm) & $22.9[19.5,26.3]$ & $22.9[19.5,25.7]$ & $23.7[19.0,29.3]$ & 0.422 \\
\hline Modified Pavlov ratio & $0.32(0.1)$ & $0.31(0.1)$ & $0.34(0.09)$ & $<0.001$ \\
\hline Presence of foraminal stenosis C4-C5 (\%) & & & & $<0.001$ \\
\hline No & $133(72.3)$ & $129(81.6)$ & $4(15.4)$ & \\
\hline Yes & $51(27.7)$ & $29(18.4)$ & $22(84.6)$ & \\
\hline Number of levels decompressed & $3.3(1.0)$ & $3.2(0.9)$ & $3.8(1.2)$ & 0.004 \\
\hline Number of fusion levels & $3.9(0.5)$ & $3.9(0.5)$ & $4.2(0.6)$ & 0.014 \\
\hline
\end{tabular}

DM diabetes mellitus, $B M I$ body mass index, JOA Japanese Orthopaedic Association, $C C l$ cervical curvature index, SVA sagittal vertical axis 
Table 2 Univariate and multivariate logistic regression model analyses of C5P in this study

\begin{tabular}{|c|c|c|c|c|c|c|c|c|}
\hline \multirow[t]{3}{*}{ Variable } & \multicolumn{4}{|c|}{ Univariable logistic regression analysis } & \multicolumn{4}{|c|}{ Multivariable logistic regression analysis } \\
\hline & \multicolumn{4}{|c|}{ Odds ratio $95 \%$ confidence interval $P$ value } & \multicolumn{4}{|c|}{ Odds ratio $95 \%$ confidence interval $P$ value } \\
\hline & & Lower & Upper & & & Lower & Upper & \\
\hline Age (years, \%) & 0.992 & 0.956 & 1.029 & 0.688 & & & & \\
\hline Sex (\%) & 1.483 & 0.642 & 3.573 & 0.363 & & & & \\
\hline History of hypertension (\%) & 0.902 & 0.284 & 2.411 & 0.847 & & & & \\
\hline DM (\%) & 1.731 & 0.687 & 4.136 & 0.226 & & & & \\
\hline History of smoking (\%) & 1.742 & 0.533 & 4.888 & 0.317 & & & & \\
\hline BMI $\left(\mathrm{kg} / \mathrm{m}^{2}, \%\right)$ & 0.973 & 0.899 & 1.047 & 0.471 & & & & \\
\hline Electromyogram abnormal (\%) & 5.747 & 2.302 & 16.46 & $0.000399 * * *$ & 7.861 & 2.139 & 19.546 & $0.003674^{* *}$ \\
\hline Pathological reflexes (\%) & 1.569 & 0.957 & 2.577 & 0.0725 & & & & \\
\hline Preoperative JOA score & 0.718 & 0.620 & 0.798 & 0.07 & & & & \\
\hline Postoperative JOA score & 1.070 & 0.926 & 1.239 & 0.3636 & & & & \\
\hline JOA recovery rate & 1.371 & 1.168 & 1.637 & $0.000221 * * *$ & 1.412 & 1.111 & 1.879 & $0.008841^{* *}$ \\
\hline Preoperative $\mathrm{CCl}$ & 1.400 & 1.124 & 1.776 & $0.00372^{* *}$ & 1.289 & 0.916 & 1.934 & 0.175568 \\
\hline Postoperative $\mathrm{CCl}$ & 1.150 & 1.009 & 1.316 & 0.0375 * & 1.138 & 0.935 & 1.399 & 0.199295 \\
\hline CCl Change & 1.205 & 0.953 & 1.533 & 0.122 & & & & \\
\hline Preoperative C2-7 SVA (mm) & 1.021 & 0.972 & 1.074 & 0.406561 & & & & \\
\hline Postoperative C2-7 SVA (mm) & 1.043 & 0.974 & 1.117 & 0.218578 & & & & \\
\hline Modified Pavlov ratio & 0.012 & 0.0075 & 0.024 & $2.57 \mathrm{e}-05^{* * *}$ & 0.021 & 0.009 & 0.034 & $0.028964 *$ \\
\hline Presence of foraminal stenosis C4-C5 (\%) & 8.231 & 4.124 & 13.214 & $3.76 \mathrm{e}-08 * * *$ & 15.492 & 3.961 & 21.654 & $0.000236^{* * *}$ \\
\hline Number of levels decompressed & 1.850 & 1.205 & 2.901 & $0.00564 * *$ & 1.525 & 0.808 & 3.006 & 0.201100 \\
\hline Number of fusion levels & 2.864 & 1.250 & 6.895 & $0.015492 *$ & 0.994 & 0.339 & 3.115 & 0.992097 \\
\hline
\end{tabular}

DM diabetes mellitus, BMI body mass index, JOA Japanese Orthopaedic Association, CCI cervical curvature index, SVA sagittal vertical axis

but may be associated with multiple factors. Until now, there have been some additional studies on the prediction of C5P. Frustratingly, it is difficult to accurately predict the incidence of $\mathrm{C} 5 \mathrm{P}$ and identify related risk factors $[20,30]$. In this research, we developed and validated an SVM model for C5P after LF in patients with $\mathrm{CM}$ based on a machine learning algorithm.

In this report, we identified four factors that were independently associated with C5P. Electromyogram abnormality was an independent predictor. Sasai et al. [31] divided 111 patients with $\mathrm{CM}$ into two groups and found that electromyography was a sensitive predictor for C5P after laminoplasty. In the present study, the proportion of abnormal electromyograms was significantly higher in the C5P group than in the No C5P group. In parallel, multivariate logistic regression analysis showed an abnormal electromyogram odds ratio (OR) value of 7.861. This suggested that abnormal electromyograms were a critical risk factor to address C5P. Abnormal electromyogram results indicated that the patient had subclinical nerve root compression, which was the pathological basis for the occurrence of C5P. Although numerous previous studies have shown that preoperative and postoperative JOA scores were not independent predictors of C5P, something interesting was observed in this study [32-36]. The JOA recovery rate was significantly higher in the C5P group than in the No C5P group and was identified as an independent risk factor for C5P. In our clinical practice, the majority of patients with C5P had a good prognosis without specific treatment. However, it was easy to overlook the fact that the onset of C5P was often accompanied by significant motor weakness and pain, which could significantly impact the clinical outcome. Cervical lordosis has been considered an essential factor in previous studies. Hence, we included it in the SVM model. Individual scholars have suggested that C5P is often associated with backward spinal cord drift. However, there remain many controversies in the existing literature [34, 37]. Therefore, there is currently no clear evidence to confirm the inevitability of the degree of posterior displacement of the spinal cord in cervical lordosis and the occurrence of C5P. In this study, the difference between the preoperative CCI of the two groups was statistically significant, and the preoperative $\mathrm{CCI}$ was greater in the $\mathrm{C5P}$ group than in the No C5P group. The CCI was reduced in both groups postoperatively, but no statistically significant difference was observed between the two groups. These 

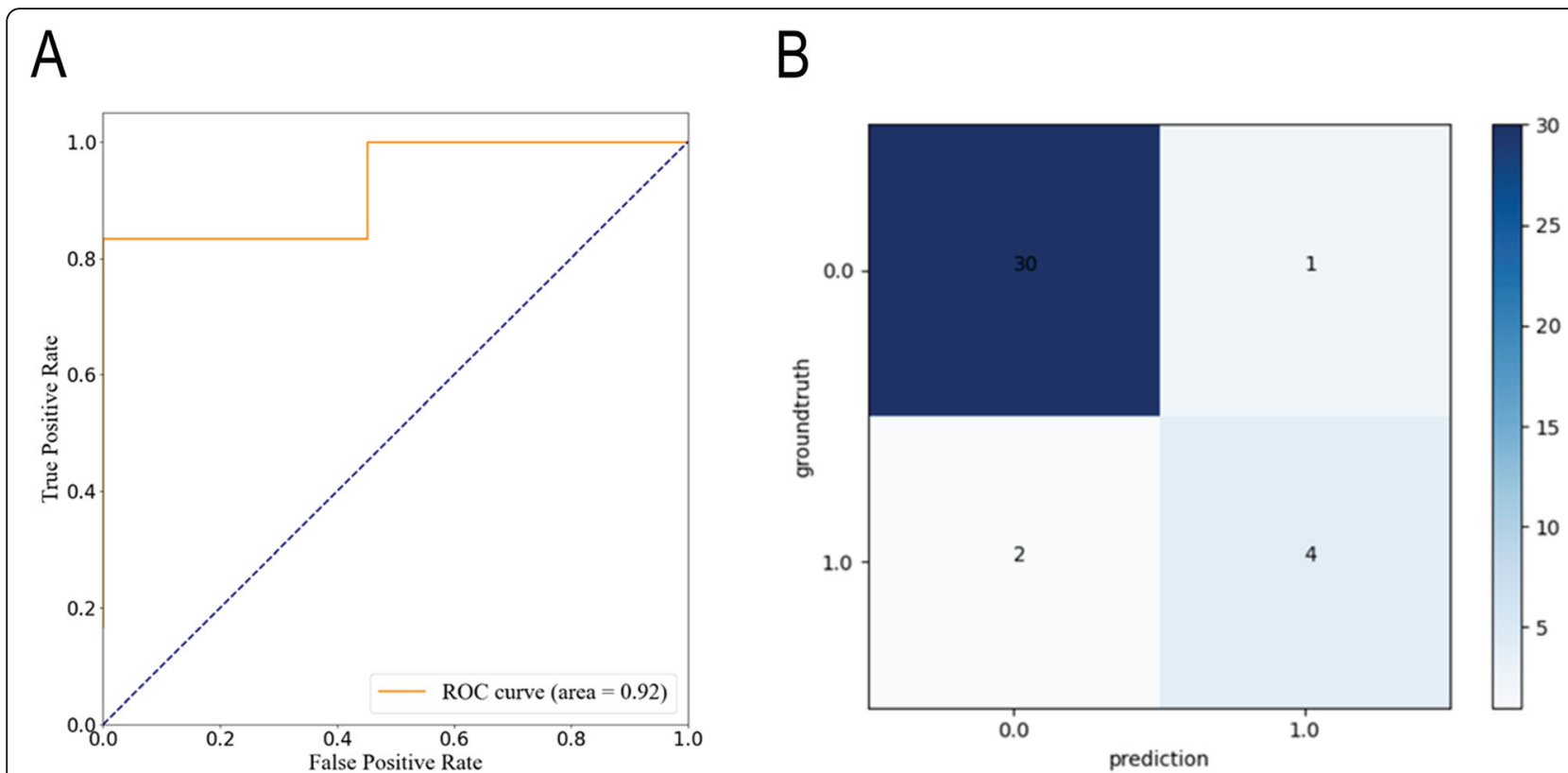

Fig. 2 a The results of the confusion matrix show good predictive ability of the SVM model. b Receiver operating characteristic curve analysis of the SVM model

results suggested that the greater the preoperative $\mathrm{CCI}$, the higher the incidence of C5P.

Remarkably, we introduced the modified Pavlov ratio. The previous Torg-Pavlov ratio shows the canal-tovertebral body ratio [20]. Although this provides a relatively concise method, false negatives frequently occurred. To investigate cords to actual compression masses, including protruding discs, regardless of bony canal stenosis, a modified Pavlov ratio was introduced in this study. Pierre et al. [38] first reported the application of a modified Pavlov ratio in the evaluation of the state of spinal cord compression, which was a more accurate and reliable imaging parameter. The relationship between C2-C7 SVA and the incidence of C5P after cervical spine surgery has been reported in few previous studies [19]. In the present study, we found no significant difference between preoperative and postoperative C2-C7 SVA in the two groups. However, previous literature has suggested that the effect of cervical sagittal balance on patients' postoperative quality of life cannot be ignored [19]. Therefore, we incorporated this parameter into the SVM model in an initial attempt to explore the association between $\mathrm{C} 2-\mathrm{C} 7$ SVA parameters and C5P. Several studies have reported that preventive $\mathrm{C} 4 / 5$ foraminotomies decrease the incidence of C5P-LP [39, 40]. Although significance was not observed in this study, a higher incidence of C5P was found in patients with C4-5 foraminal stenosis than in those without it. More importantly, this variable was identified as an independent risk factor for C5P. The width of decompression in previous studies was considered to be an important risk factor for C5P [37]. However, little research has examined the effect of the number of levels decompressed on the incidence of C5P in patients who underwent LF. In the present study, the number of levels decompressed was significantly higher in the C5P group than in the No C5P group. Although it was not statistically significant in the multifactorial logistic regression, we still believe that the number of levels decompressed affects the distance of spinal cord drift backward and may increase the incidence of C5P [41, 42]. Therefore, we think that the number of levels decompressed is an important parameter for the SVM model. One highlight of our work was using the SVM machine learning technique to predict C5P after LF in patients with CM from routinely available variables. Our model achieved an AUC of 0.923 , an ACC of 0.918 , and a satisfactory confusion matrix, which indicated that our model performed well in predicting C5P and might be widely applied in daily clinical practice.

There are some limitations to mention here. First, our study data were obtained from a single center, and the sample size was limited. Second, the conclusion of the study was restricted to the limitations of retrospective studies. Third, we only trained the SVM model with single-center data, and we lacked a sufficient sample size for the external validation cohort. Thus, large multicenter trials are needed to improve the universality of the results. Fourth, as a machine learning algorithm, this technique requires high computer hardware computing power, and the code related to the algorithm requires appropriate expertise, thus limiting a large-scale rollout. 
Finally, although we attempted to collect data on more variables potentially affecting C5P, it is possible that some important variables may have been neglected.

\section{Conclusions}

In conclusion, we conducted a multivariate logistic regression analysis of C5P predictors in patients with $\mathrm{CM}$ after LF using the SVM approach. The SVM model demonstrated satisfactory performance in predicting C5P. Additionally, the variables incorporated in the SVM model are readily available to clinicians and researchers, and they facilitate routine clinical use. Those who are predicted to suffer C5P using the SVM model may benefit from intervention. Additionally, the model can help identify medium- and high-risk patients, targeting important risk factors for modification and stratified management.

\section{Abbreviations}

C5P: C5 palsy; PLF: Posterior laminectomy and fusion; CM: Cervical myelopathy; SVM: Support vector machine; ACC: Accuracy; AUC: Area under receiver operating characteristic curve; OR: Odds ratio; JOA: Japanese Orthopaedic Association; BMI: Body mass index; CCl: Cervical curvature index; SVA: Sagittal vertical axis; CT: Computer tomography; MRI: Magnetic resonance imaging; RBF: Radial basis function; TP: True positive; TN: True negative; FP: False positive; FN: False negative

\section{Supplementary Information}

The online version contains supplementary material available at https://doi. org/10.1186/s13018-021-02476-5.

Additional file 1.

\section{Acknowledgements}

Not applicable.

\section{Authors' contributions}

HSW collected the data, analyzed the data, and drafted the manuscript. YQ supervised the project and reviewed the manuscript. ZRT, WLL, TTF, JWZ, MYK, and RPD conceived of the study, participated in its design and coordination, and helped to draft the manuscript. YQ was responsible for the whole project, designed the study, and supervised the study. All authors read and approved the final manuscript.

\section{Funding}

No funds were received in support of this work.

\section{Availability of data and materials}

The data set supporting the conclusion of this article is available on request to the corresponding author.

\section{Declarations}

\section{Ethics approval and consent to participate}

The study was approved by an institutional ethics committee at the Second Hospital of Jilin University (Ethics application number: 20151213002N). Considering that this work was a retrospective study, the ethics committee waived the requirement for informed consent from patients.

\section{Consent for publication}

Not applicable.

\section{Competing interests}

The authors declare that they have no competing interests.

\section{Author details}

'Department of Orthopedics, Second Hospital of Jilin University, 218 Ziqiang Street, Changchun, Jilin, People's Republic of China. ${ }^{2}$ School of Microelectronics, Wuhan University, Wuhan, Hubei, People's Republic of China. ${ }^{3}$ Guangxi University of Chinese Medicine, Nanning 530000, People's Republic of China. ${ }^{4}$ Department of Spinal Surgery, Liuzhou People's Hospital, Liuzhou 545000, People's Republic of China. ${ }^{5}$ Department of Endocrinology, Second Hospital of Jilin University, Changchun, Jilin, People's Republic of China.

Received: 10 March 2021 Accepted: 11 May 2021

Published online: 21 May 2021

\section{References}

1. Basaran R, Kaner T. C5 nerve root palsy following decompression of cervical spine with anterior versus posterior types of procedures in patients with cervical myelopathy. Eur Spine J. 2016;25(7):2050-9. https://doi.org/10.1007/ s00586-016-4567-4.

2. Joaquim AF, Makhni MC, Riew KD. Post-operative nerve injuries after cervical spine surgery. Int Orthop. 2019;43(4):791-5. https://doi.org/10.1007/ s00264-018-4257-4.

3. Shou F, Li Z, Wang H, Yan C, Liu Q, Xiao C. Prevalence of C5 nerve root palsy after cervical decompressive surgery: a meta-analysis. Eur Spine J. 2015;24(12):2724-34. https://doi.org/10.1007/s00586-015-4186-5.

4. Sakaura H, Hosono N, Mukai Y, Ishii T, Yoshikawa H. C5 palsy after decompression surgery for cervical myelopathy: review of the literature. Spine. 2003;28(21):2447-51. https://doi.org/10.1097/01.BRS.0000090833. 96168.3F

5. Hasegawa K, Homma T, Chiba Y. Upper extremity palsy following cervical decompression surgery results from a transient spinal cord lesion. Spine. 2007;32(6):E197-202. https://doi.org/10.1097/01.brs.0000257576.84646.49.

6. Fan D, Schwartz DM, Vaccaro AR, Hilibrand AS, Albert TJ. Intraoperative neurophysiologic detection of iatrogenic $\mathrm{C} 5$ nerve root injury during laminectomy for cervical compression myelopathy. Spine. 2002;27(22):2499502. https://doi.org/10.1097/00007632-200211150-00014.

7. Kim S, Lee SH, Kim ES, Eoh W. Clinical and radiographic analysis of C5 palsy after anterior cervical decompression and fusion for cervical degenerative disease. J Spinal Disord Tech. 2014;27(8):436-41. https://doi.org/10.1097/BSD. ob013e31826a10b0

8. Wu FL, Sun Y, Pan SF, Zhang L, Liu ZJ. Risk factors associated with upper extremity palsy after expansive open-door laminoplasty for cervical myelopathy. Spine J. 2014;14(6):909-15. https://doi.org/10.1016/j.spinee.2013.07.445.

9. Gu Y, Cao P, Gao R, Tian Y, Liang L, Wang C, et al. Incidence and risk factors of $C 5$ palsy following posterior cervical decompression: a systematic review. PLoS One. 2014;9(8):e101933. https://doi.org/10.1371/journal.pone.0101933.

10. Komagata M, Nishiyama M, Endo K, Ikegami H, Tanaka S, Imakiire A. Prophylaxis of C5 palsy after cervical expansive laminoplasty by bilateral partial foraminotomy. Spine J. 2004;4(6):650-5. https://doi.org/10.1016/j. spinee.2004.03.022.

11. Miller JA, Lubelski D, Alvin MD, Benzel EC, Mroz TE. C5 palsy after posterior cervical decompression and fusion: cost and quality-of-life implications. Spine J. 2014;14(12):2854-60. https://doi.org/10.1016/.spinee.2014.03.038.

12. Wu EQ, Zhou M, Hu D, Zhu L, Tang Z, Qiu XY, et al. Self-paced dynamic infinite mixture model for fatigue evaluation of pilots' brains. IEEE Trans Cybern. 2020;1:16. https://doi.org/10.1109/TCYB.2020.3033005.

13. Wu EQ, Peng $X$, Chen $S$, Zhao $X$, Tang Z. Detecting Alzheimer's dementia degree. IEEE Trans Cogn Dev Syst. 2020;1:1. https://doi.org/10.1109/TCDS.2 020.3015131:1

14. Wu EQ, Hu D, Deng PY, Tang Z, Cao Y, Zhang WM, et al. Nonparametric bayesian prior inducing deep network for automatic detection of cognitive status. IEEE Trans Cybern. 2020. https://doi.org/10.1109/TCYB.2020.29772 $67: 1-14$

15. Vapnik V. The nature of statistical learning theory. Berlin: Springer Science \& Business Media; 2013.

16. Vijayarajeswari R, Parthasarathy P, Vivekanandan S, Basha AA. Classification of mammogram for early detection of breast cancer using SVM classifier and hough transform. Measurement. 2019;146:800-5. https://doi.org/10.101 6/i.measurement.2019.05.083.

17. Zhao ZL, He YJ, Ouyang T. Application value of random forest and support vector machine in diagno-sing breast lesions by using ultrasonic image features. Chin J Health Stat. 2018;35:684-8. 
18. Harrison DE, Harrison DD, Cailliet R, Janik TJ, Holland B. Radiographic analysis of lumbar lordosis: centroid, Cobb, TRALL, and Harrison posterior tangent methods. Spine. 2001;26(11):e235-42. https://doi.org/10.1097/ 00007632-200106010-00003.

19. Ohara A, Miyamoto K, Naganawa T, Matsumoto K, Shimizu K. Reliabilities of and correlations among five standard methods of assessing the sagittal alignment of the cervical spine. Spine. 2006;31(22):2585-91. https://doi.org/1 0.1097/01.brs.0000240656.79060.18.

20. Kaloostian P. Preoperative risk factors of $\mathrm{C} 5$ nerve root palsy after laminectomy and fusion in patients with cervical myelopathy. Clin Spine Surg. 2017;9:419-24.

21. Statnikov A, Aliferis CF, Hardin DP, Guyon I. A gentle introduction to support vector machines in biomedicine: theory and methods. Singapore: World Scientific; 2011. https://doi.org/10.1142/7922

22. Pedregosa F, Varoquaux G, Gramfort A, Michel V, Thirion B, Grisel O, et al. Scikit-learn: machine learning in Python. J Mach Learn Res. 2011;12:2825-30.

23. Sperandei S. Understanding logistic regression analysis. Biochem Med. 2014 24:12-8.

24. Witten $I H$, Frank E. Data mining: practical machine learning tools and techniques with Java implementations. ACM SIGMOD Rec. 2002;31(1):76-7. https://doi.org/10.1145/507338.507355.

25. Witten $\mathrm{IH}$, Frank E, Hall MA, Pal CJ. Practical machine learning tools and techniques. Morgan Kaufmann. 2005;578:1.

26. Imagama S, Matsuyama Y, Yukawa Y, Kawakami N, Kamiya M, Kanemura T, et al. C5 palsy after cervical laminoplasty: a multicentre study. J Bone Jt Surg Br. 2010;92:393-400.

27. Nassr A, Eck JC, Ponnappan RK, Zanoun RR, Donaldson WF III, Kang JD. The incidence of C5 palsy after multilevel cervical decompression procedures: a review of 750 consecutive cases. Spine. 2012;37(3):174-8. https://doi.org/1 0.1097/BRS.0b013e318219cfe9.

28. Bydon M, Macki M, Kaloostian P, Sciubba DM, Wolinsky JP, Gokaslan ZL, et al. Incidence and prognostic factors of c5 palsy: a clinical study of 1001 cases and review of the literature. Neurosurgery. 2014;74(6):595-605. https:// doi.org/10.1227/NEU.0000000000000322.

29. Chen Y, Chen D, Wang X, Guo Y, He Z. C5 palsy after laminectomy and posterior cervical fixation for ossification of posterior longitudinal ligament. Clin Spine Surg. 2007;20:533-5.

30. Lubelski D, Derakhshan A, Nowacki AS, Wang JC, Steinmetz MP, Benzel EC, et al. Predicting C5 palsy via the use of preoperative anatomic measurements. Spine J. 2014;14(9):1895-901. https://doi.org/10.1016/j. spinee.2013.10.038

31. Sasai K, Saito T, Akagi S, Kato I, Ohnari H, lida H. Preventing C5 palsy after laminoplasty. Spine. 2003;28(17):1972-7. https://doi.org/10.1097/01.BRS. 0000083237.94535 .46 .

32. Takenaka S, Hosono N, Mukai Y, et al. Significant reduction in the incidence of C5 palsy after cervical laminoplasty using chilled irrigation water[J]. The bone \& joint journal. 2016;98(1):117-24.

33. Kurakawa T, Miyamoto H, Kaneyama S, Sumi M, Uno K. C5 nerve palsy after posterior reconstruction surgery: predictive risk factors of the incidence and critical range of correction for kyphosis. Eur Spine J. 2016;25(7):2060-7. https://doi.org/10.1007/s00586-016-4548-7.

34. Liu T, Kong J, Zou W, Sun Z, Yan W, Xiao J. The correlation study of C5 nerve root palsy and common body position in posterior total laminectomy decompression and instrumentation. Turk Neurosurg. 2016;26(2):280-5. https://doi.org/10.5137/1019-5149.JTN.7476-12.1.

35. Lim CH, Roh SW, Rhim SC, Jeon SR. Clinical analysis of C5 palsy after cervical decompression surgery: relationship between recovery duration and clinical and radiological factors. Eur Spine J. 2017;26(4):1101-10. https://doi.org/10.1 007/s00586-016-4664-4.

36. Wagner SC, Sebastian AS, Butler JS, Kaye ID, Morrissey PB, Hilibrand AS, et al. C5 motor palsy after single- and multi-level anterior cervical diskectomy and fusion: a retrospective review. J Am Acad Orthop Surg. 2019;27(8):e390-4. https://doi.org/10.5435/JAAOS-D-17-00764.

37. Tsuji T, Matsumoto M, Nakamura M, Ishii K, Fujita N, Chiba K, et al. Factors associated with postoperative C5 palsy after expansive open-door laminoplasty: retrospective cohort study using multivariable analysis. Eur Spine J. 2017;26(9):2410-6. https://doi.org/10.1007/s00586-017-5223-3.

38. Kang KC, Suk KS, Kim HS, et al. Preoperative Risk Factors of C5 Nerve Root Palsy After Laminectomy and Fusion in Patients With Cervical Myelopathy[J]. Clinical spine surgery. 2017:30(9):419-24.
39. Chiba K, Toyama Y, Matsumoto M, Maruiwa H, Watanabe M, Hirabayashi K Segmental motor paralysis after expansive open-door laminoplasty. Spine. 2002;27(19):2108-15. https://doi.org/10.1097/00007632-200210010-00006.

40. Kaneyama S, Sumi M, Kanatani T, Kasahara K, Kanemura A, Takabatake M, et al. Prospective study and multivariate analysis of the incidence of C5 palsy after cervical laminoplasty. Spine. 2010;35(26):E1553-8. https://doi. org/10.1097/BRS.0b013e3181ce873d.

41. Yamashita T. C5 nerve palsy after cervical laminoplasty: an analysis of three cases. Seikei Geka. 1996:47:1365-9.

42. Sodeyama T, Goto S, Mochizuki M, Takahashi J, Moriya H. Effect of decompression enlargement laminoplasty for posterior shifting of the spinal cord. Spine. 1999;24(15):1527. https://doi.org/10.1097/00007632-1 99908010-00005.

\section{Publisher's Note}

Springer Nature remains neutral with regard to jurisdictional claims in published maps and institutional affiliations.
Ready to submit your research? Choose BMC and benefit from:

- fast, convenient online submission

- thorough peer review by experienced researchers in your field

- rapid publication on acceptance

- support for research data, including large and complex data types

- gold Open Access which fosters wider collaboration and increased citations

- maximum visibility for your research: over $100 \mathrm{M}$ website views per year

At $\mathrm{BMC}$, research is always in progress.

Learn more biomedcentral.com/submissions 